\title{
Effectiveness of ${ }^{18}$ F-FDG PET/CT in the diagnosis and staging of osteosarcoma: a meta-analysis of 26 studies
}

\author{
Fanxiao Liu $^{1,2^{*}} \mathbb{D}$, Qingyu Zhang ${ }^{3+}$, Dongsheng Zhou ${ }^{1}$ and Jinlei Dong ${ }^{1}$
}

\begin{abstract}
Background: Multiple trials have attempted to assess the diagnostic value of ${ }^{18} \mathrm{~F}$-fluorodeoxyglucose positron emission tomography/computed tomography ( ${ }^{18} \mathrm{~F}-\mathrm{FDG}$ PET/CT) in osteosarcoma with results remaining inconclusive. This study aims to investigate the effectiveness of ${ }^{18} \mathrm{~F}-\mathrm{FDG}$ PET and PET/CT in the diagnosis, staging, recurrence and metastasis formation observations of osteosarcoma through systematic review followed by meta-analysis.

Methods: Three electronic databases, Medline/PubMed, Embase and the Cochrane Library were utilized in this study. Eligible studies that assessed the performance of ${ }^{18} \mathrm{~F}-\mathrm{FDG}$ PET/CT for the diagnosis, staging, restaging and recurrence monitoring of osteosarcoma were retrieved utilizing specific search criteria. After screening and diluting out the nonconforming articles, all relevant articles and their data were identified and extracted to calculate the summary metrics involving sensitivity, specificity, diagnostic odd ratio (DOR), and area under the curve (AUC) to determine the effectiveness of ${ }^{18}$ F-FDG PET in diagnosing osteosarcoma clinically.

Results: Out of 1976 articles searched, twenty-six studies were identified that were viable. All data from these articles, utilized in the quantitative analyses, showed after meta-analysis that when utilizing ${ }^{18} \mathrm{~F}$-FDG PET or PET/CT it was better with a success rate of $90-100 \%$ for detecting primary lesions and distant metastases of patients with osteosarcoma. Similar results were also obtained for detecting lung and bone metastases in a subgroup analysis.

Conclusions: As such the investigation demonstrated that ${ }^{18} \mathrm{~F}-\mathrm{FDG}$ PET and PET/CT are very accurate for the diagnosis, staging and recurrence monitoring of osteosarcoma. ${ }^{18} \mathrm{~F}$-FDG-avid lesions should be further examined in osteosarcoma, especially for suspicious lung lesions.
\end{abstract}

Keywords: ${ }^{18}$ F-FDG PET, PET/CT, Metastases, Meta-analysis, Osteosarcoma, Diagnostic accuracy

\section{Background}

Osteosarcoma is the most frequent type of primary bone malignancy in childhood and adolescence, which originates from primitive mesenchymal stem cells that improperly form osteoblasts that then deposit malignant osteoid [1]. The combination of high-dose chemotherapy and limb-salvage surgery has been shown to prolong the overall

\footnotetext{
*Correspondence: wosh631@126.com; woshi631@126.com

Fanxiao Liu and Qingyu Zhang are first author's: Contributed equally in the planning, construction and writing of the manuscript as the first author.

'Department of Orthopaedics, Shandong Provincial Hospital affiliated to Shandong University, No.324, Road Jing Wu Wei Qi, Jinan 250021, Shandong, China

${ }^{2}$ Department of Orthopaedic Surgery, Physical Medicine and Rehabilitation, University Hospital of Munich (LMU), Campus Grosshadern,

Marchioninistrasse 23, 81377 Munich, Germany

Full list of author information is available at the end of the article
}

survival of localized osteosarcoma to 65 70\% [2]. However, the prognosis of patients with radiographically discernable distant metastases is still unfavorable due to a large majority of occult metastases present in lung, and the minority in bone, lymph node and other parts of the body [3]. Moreover, after limb-salvage operations, approximately $13.5 \%$ of patients have a local recurrence of the sarcoma [4]. The outcome of local recurrent osteosarcoma is even worse than for patients with metastases alone [5]. Therefore, accuracy and early detection of local recurrence and distant metastases formation have a crucial role in the risk stratification and the treatment of osteosarcoma.

Several traditional imaging modalities have been used for the diagnosis, staging and treatment monitoring of osteosarcoma, such as plain radiographs, computed

(c) The Author(s). 2019 Open Access This article is distributed under the terms of the Creative Commons Attribution 4.0 International License (http://creativecommons.org/licenses/by/4.0/), which permits unrestricted use, distribution, and 
tomography (CT) and magnetic resonance imaging (MRI). ${ }^{18} \mathrm{~F}$-fluorodeoxyglucosepositron emission tomography $\left({ }^{18} \mathrm{~F}\right.$-FDG PET), through detecting the high uptake of ${ }^{18}$ F-FDG, a radioactive analogue of glucose, could identify sites with increased metabolic activity of various malignant tumors. More recently, PET/CT, which combines metabolic data from PET and imaging data from conventional CT, seems to be far more reliable in diagnosing malignancies.

A previous clinical study [6] had demonstrated that osteosarcoma was ${ }^{18} \mathrm{~F}$-FDG-avid. Uptake of ${ }^{18} \mathrm{~F}$-FDG was applied for the diagnosis, chemotherapy response assessment, prognosis prediction and guidance of biopsies of osteosarcoma [7]. Compared with bone scintigraphy, ${ }^{18}$ F-FDG PET and PET/CT could identify bone, lung and other metastatic lesions. Subsequently, ${ }^{18}$ F-FDG PET and PET/CT have an advantage in assessing local recurrence as they are not affected by imaging artifacts.

Multiple studies have attempted to assess the diagnostic accuracy of ${ }^{18}$ F-FDG PET and PET/CT in osteosarcoma. However, there seems to be considerable methodological variability, including the methods for evaluating the FDG uptake and the standardized uptake value (SUV) at determining whether the lesions are positive. Results remain inconclusive. Recently, two systematic review coupled meta-analyses [8-10] tried to further clarify this issue, but none of the included studies specifically aimed at osteosarcoma and did not statistically analyze the retrieved data. ${ }^{18}$ F-FDG PET or PET/CT have not been considered as the standardized components of the diagnostic algorithm for osteosarcoma. To reach a more precise result on this topic, the present study sought to systematically collected previously published data from literatures and performed a statistically evaluation using meta-analysis to see if ${ }^{18} \mathrm{~F}$-FDG PET/CT is far more efficient at diagnosing osteosarcoma then present detection paradigms.

\section{Methods}

\section{Search strategy, inclusion and exclusion criteria}

Two investigators, blinded, independently and repeatedly, performed a systematic computerized article search using three databases (Medline/PubMed, Embase and the Cochrane Library) with combinations of following key words: "positron emission tomography" [all field] OR "PET" [all field] AND "osteosarcoma" [all field] OR "bone sarcoma" [all field]. No language limitations were imposed. This search process was completed on March 1, 2018 with no language and search limitations. Additionally, bibliographies of included studies were also searched by hand to explore any potentially eligible trials.

The targeted studies in the meta-analysis had to fulfill all following criteria: a) clinical trials assessing the usefulness of ${ }^{18} \mathrm{~F}$-FDG PET or PET/CT in the diagnosis, staging, restaging and recurrence monitoring of osteosarcoma; b) patients with osteosarcoma clinically diagnosed by histopathology, follow-up or other reference methods; c) sufficient data were provided to calculate the number of true-positive (TP), false-positive (FP), false-negative (FN) and true negative (TN) cases; d) if more than one article contained overlapping data, the most comprehensive or recent article was included; and e) ${ }^{18}$ F-FDG was intravenously administered as an inducer.

Exclusion criteria for this meta-analysis were: a) in vitro or animal studies; b) trials with fewer than five participants with osteosarcoma; c) posters presented at conferences/ congresses (due to the lack of data and methodology description); d) not original research (reviews, editorials, meta-analyses, letters and comments).

\section{Data extraction and quality assessment}

The following main information were extracted from original articles: first author's surname, year of publication, source of studies, basic characteristics of the participants (numbers, age and gender), study design, inclusion interval, technical details (image devices, injection dose and methods of image analysis) and the time between injection and image acquisition). Additionally, the cases of TP, FP, TN and FN were extracted directly or recalculated through data presented in original articles based on different lesions such as primary, recurrence and metastases of lung and bone.

The methodological quality of included studies was appraised utilizing the QUADAS tool [11], which is composed of 14 items. Study following at least nine items of these scores was deemed as high quality and was included in this investigation.

\section{Statistical analysis}

This systematic review and meta-analysis confirmed the standardized items described by "the Preferred Reporting Items for Systematic Reviews and Meta-Analyses (PRISMA)" statement [12]. To assess the accuracy of ${ }^{18}$ F-FDG PET and PET/CT on the diagnosis, staging and recurrence monitoring of osteosarcoma, the pooled estimates included the sensitivity, specificity, positive likelihood ratio (PLR), negative likelihood ratio (NLR), diagnostic odd ratio (DOR) and the summary receiver operating characteristic curve (sROC) and AUC. Following recommendations of Cochrance Handbook (www.cochrance.org/trainig/ cochrance-handbook), study-heterogeneity was evaluated using Chi-squared and I-square statistic algorithms. Low heterogeneity was defined as I-square $<50 \%$ and with P> 0.1 . To obtain a reliable result, all analyses were performed using the random-effect model. The DOR is an indicator of the test accuracy, ranging from zero to infinity. A higher DOR indicates that the test is more accurate. The areas under the curve (AUC) and Q*-index are two important statistics that reflect the diagnostic value. The AUC is 
defined as the area under sROC, and $\mathrm{Q}^{*}$ is the point where the sensitivity is equal to the specificity. The statistical analyses for the detection of primary lesions, recurrence, lung metastases, bone metastases and all distant metastases were performed separately.

\section{Results}

\section{Study selection}

At primary retrieval, a total of 1952 articles were identified, based on the search criteria, of which 1892 were subsequently deemed non-viable after inclusion and exclusion criteria were applied. Out of the 84 articles resulting from preliminary screening, 37 articles were referred to irrelevant studies, 5 articles were duplicate publications and 21 articles lacked sufficient data to calculate evaluation indicators and were excluded from the meta-analysis. The remaining 26 studies [13-38] deemed viable, published from 1998 to 2017, were included in the meta-analysis. Although five of the trials [14-18] showed signs of having utilized the same patients, these were included in a different subgroup analyses. The selection process and reasons other articles were excluded are described in Fig. 1.

\section{Characteristics of included studies}

The basic characteristics of the 26 included studies are summarized in Table 1. The sizes of patients in the studies ranged from 5 to 206, and a total of 798 osteosarcoma patients were included. A total of 17 studies were retrospective design types whereas 8 studies were prospective. Based on the QUADAS score, only one study [22] had a score of
9 , nine studies $[14,16-18,25,30,31,34,35]$ had a score of 11 , five studies $[15,21,23,24,32]$ a score of 12 with all remaining studies $[13,19,20,26-29,33,36-38]$ possessing a score of 13 . The major information of PET or PET/ CT imaging of each study was summarized in Table 2 . Among them, sixteen studies presented that image acquisition were performed approximately $60 \mathrm{~min}$ after FDG injection. The results of whole-body ${ }^{18}$ F-FDG PET or PET-CT were analyzed visually by experienced radiologists in 7 studies [13, 20, 22, 30,31,34,37] and by standardized uptake values in 19 studies [14-19, 21, 23-29, 32, 33, 35, 36, 38]. The diagnostic data (TPs, FPs, TNs and FNs) were extracted directly or calculated through data provided in the tables or bodies of each original article (Table 3).

\section{Primary lesion}

The diagnosis of the primary lesion was analyzed on a patient-based level. Fourteen studies [13, 15, 19, 21-27, 30, 32, 33, 36] with 243 patients, with known osteosarcoma, were available. There were no threshold effects in this data $(p$-value $=1.000)$. All primary lesions were FDG-avid. The combined sensitivity of ${ }^{18}$ F-FDG PET and PET/CT in the detection of osteosarcoma was $100 \%$, while no specificity could be obtained. There was no statistically significant heterogeneity in these estimates of sensitivity (I-square $=0.0 \%$ ).

\section{Recurrence}

Results assessing the diagnostic performance of ${ }^{18} \mathrm{~F}$-FDG $\mathrm{PET}$ and PET/CT for detecting recurrence of osteosarcoma as generated from the 7 studies [18, 24, 28, 29, 35, 37, 38],

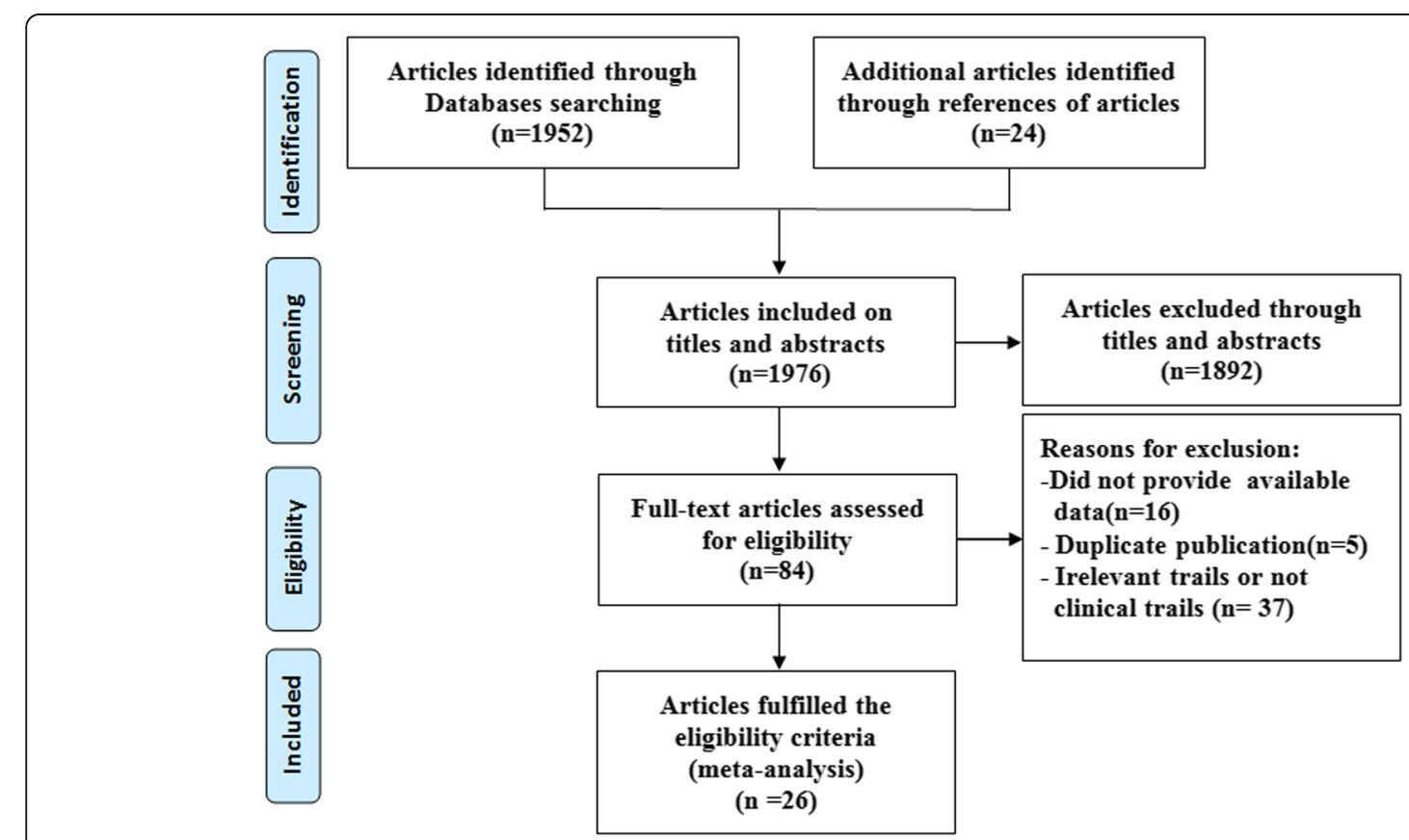

Fig. 1 Selection process for studies included in the meta-analysis 
Table 1 Main characteristics of the included studies

\begin{tabular}{|c|c|c|c|c|c|c|c|c|}
\hline Study, year & Country & $\begin{array}{l}\text { No. of } \\
\text { Subjects }\end{array}$ & $\begin{array}{l}\text { Gender } \\
(\mathrm{M} / \mathrm{F})\end{array}$ & $\begin{array}{l}\text { Median/Mean } \\
\text { age (years) }\end{array}$ & $\begin{array}{l}\text { Age range } \\
\text { (years) }\end{array}$ & Design & Inclusion interval & $\begin{array}{l}\text { QUADAS } \\
\text { scores }\end{array}$ \\
\hline Kole,1998 [13] & Netherlands & 5 & $3 / 2$ & $20 / 20.2$ & $17-24$ & Retrospective & NR & 13 \\
\hline Schulte,1999 [14] & Germany & 27 & $17 / 10$ & $17 / N R$ & $5-36$ & Prospective & Jan.1993-NR & 11 \\
\hline Franzius,2000 [15] & Germany & 32 & NR & NR & $N R$ & Retrospective & Aug.1995-Jun.1999 & 11 \\
\hline Schulte,2000 [16] & Germany & 44 & NR & $N R$ & $N R$ & Retrospective & Jan.1993-NR & 12 \\
\hline Franzius,2001 [17] & Germany & 32 & $N R$ & $N R$ & $N R$ & Retrospective & Aug.1995-Jun.1999 & 11 \\
\hline Franzius,2002 [18] & Germany & 6 & $N R$ & NR & NR & Retrospective & NR & 11 \\
\hline Yanagawa,2003 [19] & Japan & 5 & $4 / 1$ & $14 / 14.4$ & $11-20$ & Prospective & Jun.1999-Mar.2000 & 13 \\
\hline Kneisl,2006 [20] & USA & 38 & NR & $N R$ & $N R$ & Retrospective & Dec.1994-Nov.2004 & 13 \\
\hline lagaru,2006 [21] & USA & 6 & $N R$ & NR & $N R$ & Retrospective & Jan.2003-Dec.2005 & 12 \\
\hline Volker,2007 [22] & Germany & 11 & $N R$ & NR & $1-18$ & Prospective & Dec.2003-Oct.2006 & 9 \\
\hline Shin,2008 [23] & South Korea & 7 & NR & NR & $6-79$ & Retrospective & May.2004-Jun.2007 & 12 \\
\hline Charest,2009 [24] & Canada & 24 & NR & NR & NR & Retrospective & May.2004-Apr.2008 & 12 \\
\hline Hawkins,2009 [25] & USA & 40 & NR & 15.1/NR & $7.1-31$ & Prospective & Jul.1995-Aug.2004 & 11 \\
\hline Benz,2010 [26] & USA & 6 & $2 / 4$ & $27 / 30.8$ & $18-58$ & Prospective & Feb.2005-Nov.2007 & 13 \\
\hline Lindholm,2011 [27] & Finland & 6 & $4 / 2$ & $16.5 / 16.5$ & $15-18$ & Prospective & $N R$ & 13 \\
\hline Bandopadhyaya,2012 [30] & India & 22 & $14 / 8$ & $21.55 / \mathrm{NR}$ & $8-66$ & Prospective & NR & 13 \\
\hline Cistaro,2012 [28] & Italy & 11 & NR & NR/14 & NR & NR & $N R$ & 13 \\
\hline Ozkan,2012 [29] & Turkey & 7 & $6 / 1$ & $25 / 26.1$ & $18-50$ & Retrospective & 2007-2009 & 11 \\
\hline Bai,2013 [33] & China & 14 & $9 / 5$ & $N R / 14.9$ & $8-22$ & Retrospective & Jan.2009-Nov.2011 & 13 \\
\hline Byun,2013 [31] & South Korea & 206 & $127 / 79$ & $15 / \mathrm{NR}$ & $4-71$ & Retrospective & Jan.2006-Nov.2011 & 11 \\
\hline Kong,2013 [32] & South Korea & 26 & $16 / 10$ & $N R / 21$ & $9-55$ & Prospective & May.2010-Aug.2011 & 12 \\
\hline Chang,2015 [35] & South Korea & 109 & $74 / 35$ & NR/17 & NR & Retrospective & Feb.2002-Sep.2012 & 11 \\
\hline Quartuccio,2015 [34] & Italy & 20 & $10 / 10$ & 15.5/NR & NR & Retrospective & Jan.2006-Sep.2010 & 11 \\
\hline Hurley, 2016 [36] & USA & 39 & $19 / 20$ & Median 12 & $5-19$ & Retrospective & 2003-2012 & 13 \\
\hline Angelini, 2017 [38] & Italy & 37 & 20/17 & Mean 20 & $7-52$ & Retrospective & 2008-2014 & 13 \\
\hline Sharp, 2017 [37] & USA & 8 & $5 / 3$ & Median 13 & $8-16$ & Retrospective & Oct.2004-Feb. 2013 & 13 \\
\hline
\end{tabular}

$M$ male, $F$ female, $N R$ not reported

showed that the pooled sensitivity of $91 \%$ (95\% CI of $81-$ 96\%), a specificity of 93\% (95\% CI of $87-97 \%$ ), a PLR of 7.36 (95\% CI of 3.54-15.30), a NLR of 0.14 (95\% CI of 0.07-0.29), a DOR of 63.98 (95\% CI of 19.29-212.18), the Q*index of 0.8842 and AUC of 0.9452 (Fig. 2). No significance of heterogeneity between study for the pooled sensitivity (I-square $=0.0 \%)$ and the threshold effect ( $p$-value $=$ 0.269 ) were presented in this analysis.

\section{Lung metastases}

In total, 8 studies $[14,17,28-30,33,34,38]$ addressed the diagnosis of lung metastases. The threshold effects was no found in the data ( $\mathrm{p}$-value $=0.233$ ). The combined sensitivity of ${ }^{18}$ F-FDG PET and PET/CT in detecting lung metastases of osteosarcoma was $81 \%$ (95\% CI of $72-88 \%$ ), specificity $94 \%$ (95\% CI of $89-97 \%$ ), PLR 8.13 (95\% CI of $4.19-15.77)$ and NLR 0.26 (95\% of CI $0.17-0.40)$. The pooled DOR was 48.85 (95\% CI of
18.92-126.14), whereas the $Q^{*}$-index was 0.8614 with an AUC of 0.9268 (Fig. 3).

\section{Bone metastases}

Results assessing the diagnostic performance of ${ }^{18} \mathrm{~F}$-FDG $\mathrm{PET}$ and PET/CT for detecting bone metastasis of osteosarcoma as generated from the 6 studies $[22,29,31,33,34$, 36], demonstrated that the pooled sensitivity of $93 \%(95 \%$ CI of $87-97 \%$ ), a specificity of $97 \%$ (95\% CI of $96-98 \%$ ), a PLR of 9.81 (95\% CI of 2.73-35.29), a NLR of 0.08 (95\% CI of 0.04-0.18), a DOR of 174.19 (95\% CI of 38.37-790.76), the Q"-index of 0.9397 and the AUC of 0.9813 (Fig. 4). No significance of heterogeneity between study for the pooled sensitivity (I-square $=33.8 \%$ ) and the threshold effect $(p$-value $=0.8279)$ were presented in this analysis.

\section{All distant metastases}

In total, 11 studies [14, 17, 22, 28-31, 33, 34, 36, 38] addressed the diagnosis of all distant metastases. There were 
Table 2 Technical aspects of the included studies

\begin{tabular}{|c|c|c|c|c|}
\hline Study, year & Image device & Injected dose & Time between injection and image acquisition & PET image analysis \\
\hline Kole, 1998 [13] & PET & $370 \mathrm{MBq}$ & $50 \mathrm{~min}$ & Visual \\
\hline Schulte, 1999 [14] & PET & $120-300 \mathrm{MBq}$ & $45-60 \min$ & Visual and semiquantitative \\
\hline Franzius, 2000 [15] & PET & $3.7 \mathrm{MBq} / \mathrm{kg}$ & $60 \mathrm{~min}$ & Visual and semiquantitative \\
\hline Schulte, $2000[16]$ & PET & $120-300 \mathrm{MBq}$ & $45-60 \mathrm{~min}$ & Visual and semiquantitative \\
\hline Franzius, 2001 [17] & PET & $3.7 \mathrm{MBq} / \mathrm{kg}$ & $60 \mathrm{~min}$ & Visual and semiquantitative \\
\hline Franzius, 2002 [18] & PET & $3.7 \mathrm{MBq} / \mathrm{kg}$ & $60 \mathrm{~min}$ & Visual and semiquantitative \\
\hline Yanagawa, 2003 [19] & PET & $4.5 \mathrm{MBq} / \mathrm{kg}$ & $50 \mathrm{~min}$ & Visual and semiquantitative \\
\hline Kneisl, 2006 [20] & PET & $444-740 \mathrm{MBq}$ & $60 \mathrm{~min}$ & Visual \\
\hline lagaru, $2006[21]$ & $\mathrm{PET} / \mathrm{CT}$ & $151.7-721.5 \mathrm{MBq}$ & $60 \mathrm{~min}$ & Visual and semiquantitative \\
\hline Volker, 2007 [22] & PET & $N R$ & NR & Visual \\
\hline Shin, 2008 [23] & $\mathrm{PET} / \mathrm{CT}$ & $8.14 \mathrm{MBq} / \mathrm{kg}$ & $60 \mathrm{~min}$ & Visual and semiquantitative \\
\hline Charest, 2009 [24] & $\mathrm{PET} / \mathrm{CT}$ & $379-500 \mathrm{MBq}$ & $60 \mathrm{~min}$ & Visual and semiquantitative \\
\hline Hawkins, 2009 [25] & PET & 259-370 MBq & $45 \mathrm{~min}$ & Visual and semiquantitative \\
\hline Benz, 2010 [26] & $\mathrm{PET} / \mathrm{CT}$ & $7.77 \mathrm{MBq} / \mathrm{kg}$ & $60 \mathrm{~min}$ & Visual and semiquantitative \\
\hline Lindholm, 2011 [27] & $\mathrm{PET} / \mathrm{CT}$ & $370 \mathrm{MBq}$ & $60 \mathrm{~min}$ & Visual and semiquantitative \\
\hline Bandopadhyaya, 2012 [30] & $\mathrm{PET} / \mathrm{CT}$ & $370 \mathrm{MBq}$ & $60 \mathrm{~min}$ & Visual \\
\hline Cistaro, 2012 [28] & $\mathrm{PET} / \mathrm{CT}$ & $120-277 \mathrm{MBq}$ & $60 \mathrm{~min}$ & Visual and semiquantitative \\
\hline Ozkan, 2012 [29] & $\mathrm{PET} / \mathrm{CT}$ & $555 \mathrm{MBq}$ & $60 \mathrm{~min}$ & Visual and semiquantitative \\
\hline Bai, 2013 [33] & $\mathrm{PET} / \mathrm{CT}$ & 3.5-5.7 MBq/kg & $40-60 \mathrm{~min}$ & Visual and semiquantitative \\
\hline Byun, 2013 [31] & $\mathrm{PET} / \mathrm{CT}$ & $7.4 \mathrm{MBq} / \mathrm{kg}$ or $370 \mathrm{MBq}$ & $60 \mathrm{~min}$ & Visual \\
\hline Kong, 2013 [32] & $\mathrm{PET} / \mathrm{CT}$ & $8.14 \mathrm{MBq} / \mathrm{kg}$ & NR & Visual and semiquantitative \\
\hline Chang, 2015 [35] & $\mathrm{PET} / \mathrm{CT}$ & $7.4 \mathrm{MBq} / \mathrm{kg}$ or $370 \mathrm{MBq}$ & $60 \mathrm{~min}$ & Visual and semiquantitative \\
\hline Quartuccio, 2015 [34] & $\mathrm{PET} / \mathrm{CT}$ & $113-596 \mathrm{MBq}$ & $72 \mathrm{~min}$ & Visual \\
\hline Hurley, 2016 [36] & $\mathrm{PET} / \mathrm{CT}$ & $5.55 \mathrm{MBq} / \mathrm{kg}$ & $60 \mathrm{~min}$ & Visual and semiquantitative \\
\hline Angelini, 2017 [38] & $\mathrm{PET} / \mathrm{CT}$ & $5.55 \mathrm{MBq} / \mathrm{kg}$ & NR & Visual and semiquantitative \\
\hline Sharp, 2017 [37] & $\mathrm{PET} / \mathrm{CT}$ & 5.18 or $5.55 \mathrm{MBq} / \mathrm{kg}$ & $60 \mathrm{~min}$ & Visual \\
\hline
\end{tabular}

NR not reported

no threshold effects in this data ( $p$-value $=0.647)$. The combined sensitivity of ${ }^{18} \mathrm{~F}$-FDG PET and PET/CT in detecting all distant metastases of osteosarcoma was 90\% (95\% CI of $86-93 \%$ ), specificity $96 \%$ (95\% CI of $95-97 \%$ ), PLR 13.81 (95\% CI of 5.77-33.06) and NLR 0.13 (95\% CI of $0.07-0.23)$. Statistically heterogeneity was no found in the estimates of the DOR (I-square $=49.8 \%)$. The pooled DOR was 125.67 (95\% CI of 48.54-325.35). The Q*-index was 0.9103 with an AUC of 0.9639 (Fig. 5). To explore whether the injected dose of 18F-FDG could affect the diagnostic accuracy of all distant metastases, we performed a subgroup analysis which demostrated that 18F-FDG PET/CT, using a injected dose above $5 \mathrm{MBq} / \mathrm{kg}$, is similar to that using a lower dose (sensitivity of $88 \%$ [95\% CI 76-95\%] vs. 88\% [95\% CI 78-95\%]; specificity of 93\% [95\% CI 97-99\%] vs. 98\% [95\% CI 97-99\%]).

\section{Discussion}

Osteogenic sarcoma has an elevated rate of glycolysis and, consequently, a high uptake of ${ }^{18} \mathrm{~F}$-FDG in malignant cells
[39] . A previous meta-analysis [40] revealed that the standardized uptake values before (SUV1) and after (SUV2) chemotherapy in osteosarcoma were associated with the histological response. SUV2:1< 0.5 or SUV2 $<2.5$ had predictive significance for tumor necrosis. Multiple studies investigated the diagnostic value of ${ }^{18}$ F-FDG PET and $\mathrm{PET} / \mathrm{CT}$ for osteosarcoma, but no definitive results were obtained. To settle these questions scientifically, in the present study, a rigorous inclusion criterion was predesigned to collect published articles as comprehensive as possible and subgroup analyses were conducted to pool outcome estimates from individual studies only utilizing the random-effect modeling. Importantly, this is the first meta-analysis evaluating the diagnostic utility of ${ }^{18} \mathrm{~F}$-FDG $\mathrm{PET} / \mathrm{CT}$ in osteosarcoma. By systemically analyzing the retrieved data, investigations demonstrated that ${ }^{18} \mathrm{~F}-\mathrm{FDG}$ PET/CT had an excellent accuracy in the diagnosis, staging and restaging of osteosarcoma.

The value of PET in the differential diagnosis of bone tumor and tumor-like lesions was first described by 
Table 3 Diagnosis accuracy data on each examination- or lesion-based analysis

\begin{tabular}{|c|c|c|c|c|c|c|}
\hline Study, year & Total & TP & FP & FN & TN & Lesions sites \\
\hline Kole, 1998 [13] & 5 & 5 & 0 & 0 & 0 & Primary lesion \\
\hline Schulte, 2000 [14] & 44 & 44 & 0 & 0 & 0 & Primary lesion \\
\hline Yanagawa, 2003 [19] & 5 & 5 & 0 & 0 & 0 & Primary lesion \\
\hline lagaru, 2006 [21] & 6 & 6 & 0 & 0 & 0 & Primary lesion \\
\hline Volker, 2007 [22] & 11 & 11 & 0 & 0 & 0 & Primary lesion \\
\hline Shin, 2008 [23] & 7 & 7 & 0 & 0 & 0 & Primary lesion \\
\hline Charest, 2009 [24] & 12 & 12 & 0 & 0 & 0 & Primary lesion \\
\hline Hawkins, 2009 [25] & 40 & 40 & 0 & 0 & 0 & Primary lesion \\
\hline Benz, 2010 [26] & 6 & 6 & 0 & 0 & 0 & Primary lesion \\
\hline Lindholm, 2011 [27] & 6 & 6 & 0 & 0 & 0 & Primary lesion \\
\hline Bandopadhyaya, 2012 [30] & 22 & 22 & 0 & 0 & 0 & Primary lesion \\
\hline Bai, 2013 [33] & 14 & 14 & 0 & 0 & 0 & Primary lesion \\
\hline Kong, 2013 [32] & 26 & 26 & 0 & 0 & 0 & Primary lesion \\
\hline Hurley, 2016 [36] & 39 & 39 & 0 & 0 & 0 & Primary lesion \\
\hline Franzius, 2002 [18] & 6 & 6 & 0 & 0 & 0 & Recurrence \\
\hline Charest, 2009 [24] & 12 & 6 & 0 & 1 & 5 & Recurrence \\
\hline Cistaro, 2012 [28] & 11 & 10 & 0 & 0 & 1 & Recurrence \\
\hline Ozkan, 2012 [29] & 8 & 3 & 0 & 0 & 5 & Recurrence \\
\hline Chang, 2015 [35] & 109 & 7 & 6 & 2 & 94 & Recurrence \\
\hline Angelini, 2017 [38] & 37 & 22 & 0 & 1 & 14 & Recurrence \\
\hline Sharp, 2017 [37] & 10 & 10 & 0 & 0 & 0 & Recurrence \\
\hline Schulte, 1999 [14] & 27 & 4 & 0 & 0 & 23 & Lung \\
\hline Franzius, 2001 [17] & 49 & 4 & 0 & 4 & 41 & Lung \\
\hline Bandopadhyaya, 2012 [30] & 22 & 10 & 1 & 0 & 11 & Lung \\
\hline Cistaro, 2012 [28] & 23 & 16 & 0 & 3 & 4 & Lung \\
\hline Ozkan, 2012 [29] & 8 & 1 & 0 & 0 & 7 & Lung \\
\hline Bai, 2013 [33] & 14 & 2 & 0 & 0 & 12 & Lung \\
\hline Quartuccio, 2015 [34] & 56 & 27 & 5 & 5 & 19 & Lung \\
\hline Angelini, 2017 [38] & 37 & 12 & 0 & 3 & 22 & Lung \\
\hline Volker, 2007 [22] & 31 & 28 & 0 & 3 & 0 & Bone \\
\hline Ozkan, 2012 [29] & 8 & 1 & 0 & 0 & 7 & Bone \\
\hline Bai, 2013 [33] & 14 & 7 & 0 & 0 & 7 & Bone \\
\hline Byun, 2013 [31] & 833 & 52 & 15 & 3 & 763 & Bone \\
\hline Quartuccio, 2015 [34] & 21 & 16 & 1 & 0 & 4 & Bone \\
\hline Hurley, 2016 [36] & 40 & 5 & 3 & 0 & 32 & Bone \\
\hline Schulte,1999 [14] & 27 & 4 & 0 & 0 & 23 & All metastatic lesions \\
\hline Franzius, 2001 [17] & 49 & 4 & 0 & 4 & 41 & All metastatic lesions \\
\hline Volker, 2007 [22] & 42 & 31 & 0 & 3 & 8 & All metastatic lesions \\
\hline Bandopadhyaya, 2012 [30] & 22 & 10 & 1 & 0 & 11 & All metastatic lesions \\
\hline Cistaro, 2012 [28] & 38 & 27 & 2 & 3 & 6 & All metastatic lesions \\
\hline Ozkan, 2012 [29] & 8 & 3 & 0 & 0 & 5 & All metastatic lesions \\
\hline Bai, 2013 [33] & 28 & 9 & 0 & 0 & 19 & All metastatic lesions \\
\hline Byun, 2013 [31] & 833 & 52 & 15 & 3 & 763 & All metastatic lesions \\
\hline Quartuccio, 2015 [34] & 101 & 59 & 9 & 5 & 28 & All metastatic lesions \\
\hline
\end{tabular}


Table 3 Diagnosis accuracy data on each examination- or lesion-based analysis (Continued)

\begin{tabular}{lllllll}
\hline Study, year & Total & TP & FP & FN & TN & Lesions sites \\
\hline Hurley, 2016 [36] & 105 & 20 & 8 & 4 & 73 & All metastatic lesions \\
Angelini, 2017 [38] & 74 & 29 & 1 & 3 & 41 & All metastatic lesions
\end{tabular}

TP True positive, FP False positive, FN False negative, TN True negative

Schulte et al.(2000) [15]. Using a tumor-to-background ratio of 3.0 as the cutoff for determining malignant bone lesions, the sensitivity, specificity and accuracy were $0.93,0.667$ and 0.817 , respectively. Although there were several false negative cases, there were none for patients with osteosarcoma $(n=44)$. A subsequent meta-analysis [41] also reported the outstanding ability of ${ }^{18}$ F-FDG PET to distinguish between benign and malignant bone and soft tissue tumors. In studies included in the present meta-analysis, all primary osteosarcoma lesions $(n=243)$ were ${ }^{18} \mathrm{~F}$-FDG-avid with a good pooled sensitivity of $100 \%$. However, it must be noted, that as a nonspecific manifestation on ${ }^{18} \mathrm{~F}$-FDG PET, osteosarcoma is not distinctly discernible from other highly malignant bone sarcomas, such as Ewing sarcoma [42].

Detecting recurrent or residual osteosarcoma has been a challenge for clinicians due to the post-therapeutic changes and imaging artifacts caused by metallic endoprothesis [43]. In 1996, Garcia and co-workers reported the diagnostic value of ${ }^{18} \mathrm{~F}$-FDG PET in 48 suspected recurrent musculoskeletal sarcomas (including 18 osteosarcoma patients), indicating a good sensitivity and specificity (98 and $90 \%$, respectively) [44]. ${ }^{18}$ F-FDG PET has an advantage in assessing local recurrence because it is not affected by the imaging artifact. Nevertheless, elevated ${ }^{18}$ F-FDG uptake could be affected by post-treatment changes, irrespective of local recurrence $[45,46]$. In this investigation, a good accuracy was observed of ${ }^{18} \mathrm{~F}$-FDG PET in detecting recurrent osteosarcoma (local relapses or distant metastases), which are similar to the conclusions for other recurrent malignant tumors $[47,48]$.

Although osteosarcoma has a tendency to metastasize early, which would modify the outcome of osteosarcoma with an unfavorable survival, the prognosis of patients with resectable metastatic lesions is relatively good [49-51]. ${ }^{18} \mathrm{~F}$-FDG PET and PET/CT are useful tools for detecting possible malignant lesions. Therefore, a subgroup analysis was performed on the metastasis-based data in the presented study.

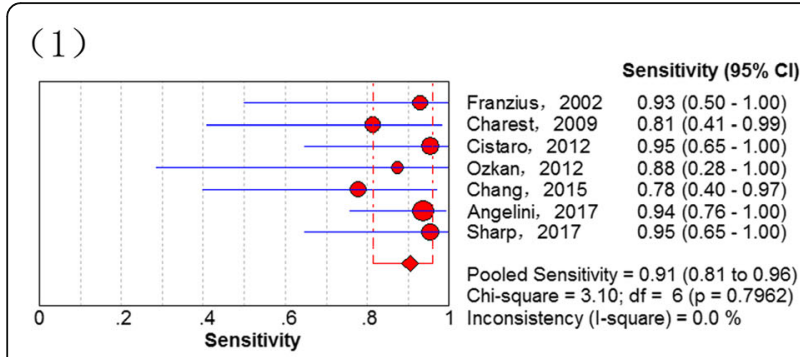

(3)

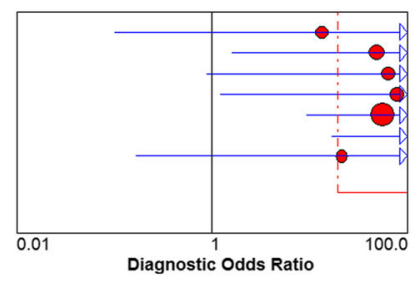

Franzius, 2002 Charest, 2009 Cistaro, 2012 Ozkan, 2012 Angelini, 2017 Sharp, 2017 Random Effects Model Cochran- $Q=2.07 ; \mathrm{df}=6(\mathrm{p}=0.9131)$ Inconsistency (I-square) $=0.0 \%$
Tau-squared $=0.0000$ Diagnostic Odds Ratio
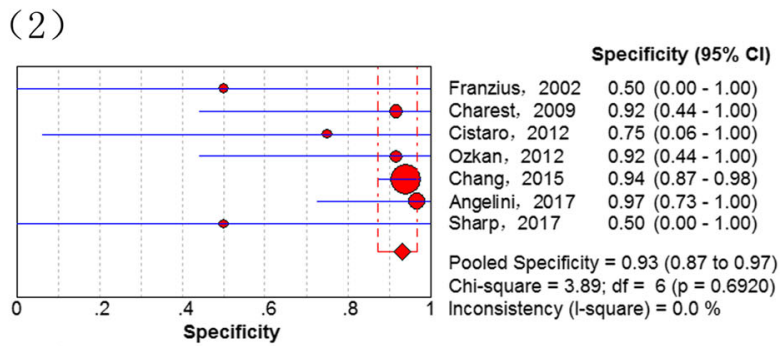

(4)

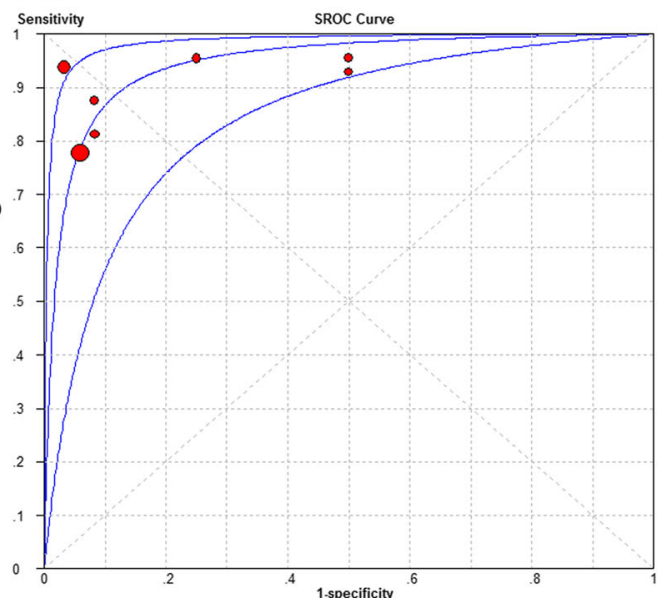

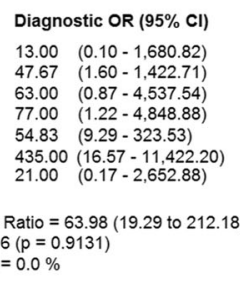
$335.00(16.57-11,422.20)$ $=63.98(19.29$ to 212.18$)$

Fig. 2 Diagnostic performance of 18F-FDG PET and PET/CT for the recurrence of osteosarcoma: (1) Pooled sensitivity (2) Pooled specificity (3) Pooled diagnostic odds ratio (4) Summary receiver operating characteristic curve (sROC) with the $\mathrm{Q}^{*}$-index 

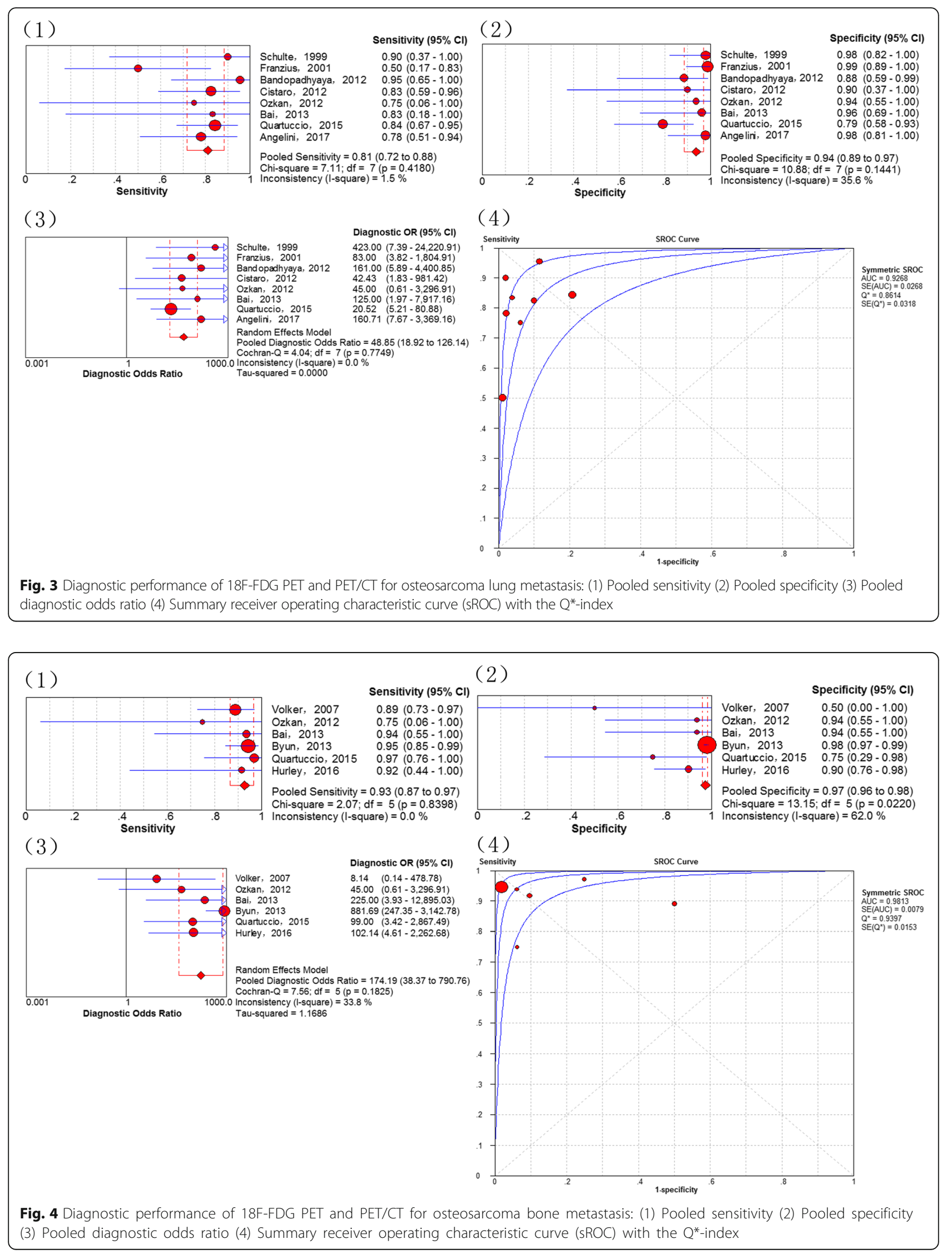


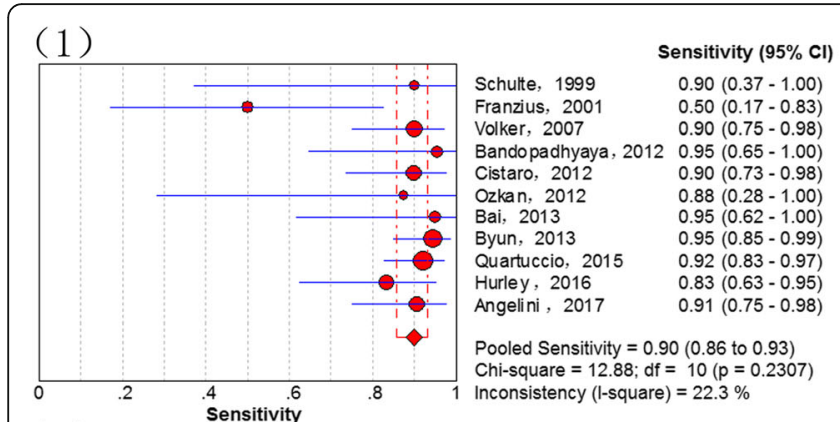

(3)

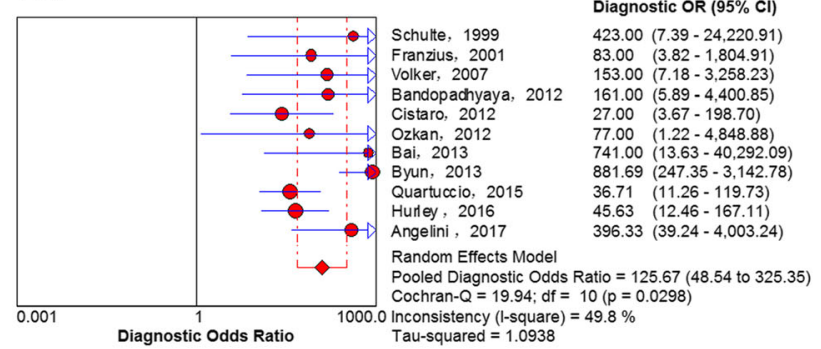

(2) Specificity $(95 \%$ C (1)

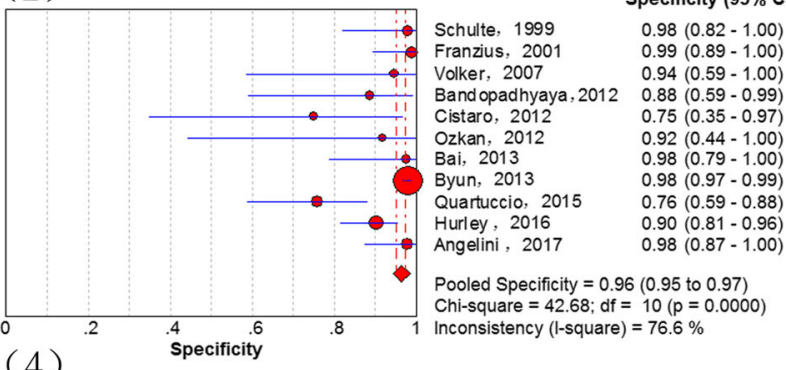

(4)

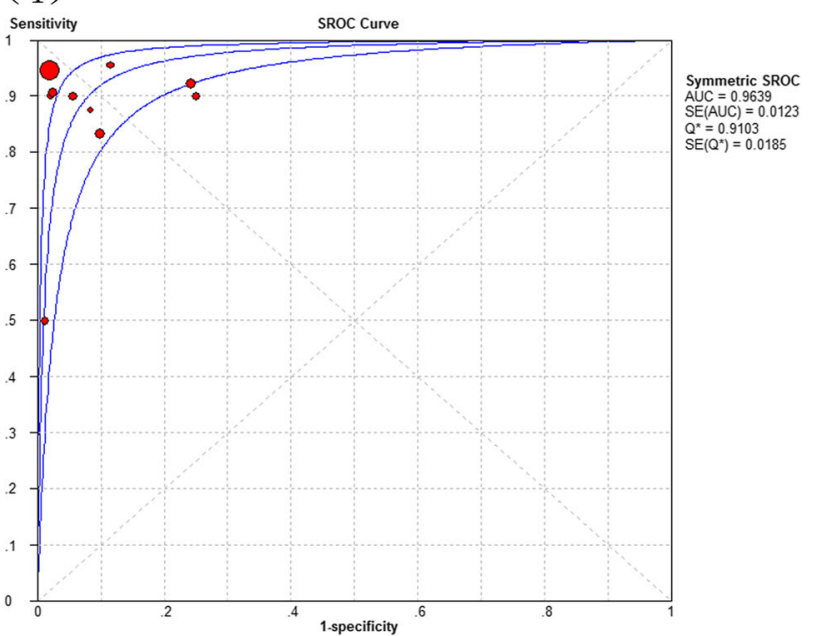

Fig. 5 Diagnostic performance of 18F-FDG PET and PET/CT for all distant metastases of osteosarcoma: (1) Pooled sensitivity (2) Pooled specificity (3) Pooled diagnostic odds ratio (4) Summary receiver operating characteristic curve (sROC) with the $\mathrm{Q}^{*}$-index

Lung metastasis ranks as the leading cause of osteosarcoma-related death [2]. Schulte et al. (1999) [14] first reported the diagnostic performance of PET for detecting osteosarcoma lung metastasis. In the presented investigation a total of 27 scans included 4 true positive and 23 true negative cases. However, Iagaru et al. (2006) [20] of 106 bone and soft tissue sarcomas suggested that PET-false positive cases were significantly increased in sub-centimeter lung metastases. Cistaro et al. (2012) [28] published data on 18 participants (11 osteosarcomas), who underwent $31 \mathrm{PET} / \mathrm{CT}$ scans where it was demonstrated that there was no significant advantage of the SUVmax or SUVratio in the evaluation of lung nodules of $<6 \mathrm{~mm}$. This may explain the lower sensitivity of ${ }^{18}$ F-FDG PET and PET/CT in the diagnosis of lung metastases compared to bone metastases in the present meta-analysis. Compared to those who only have lung metastasis, the survival for patients with osteosarcoma who have bone metastasis is even poorer [5]. Because there are many possible metastatic bones in osteosarcoma, whole-body screening is indispensable. In the diagnosis of bone metastases, our investigations revealed a remarkable sensitivity, specificity and $Q *$-index (0.93, 0.97 and 0.9397, respectively) for ${ }^{18}$ F-FDG PET and
PET/CT. Bone scintigraphy is another commonly used functional modality, while previous studies have shown that ${ }^{18}$ F-FDG PET and PET/CT are superior to bone scintigraphy in detecting bone metastases of osseous sarcoma, including osteosarcoma [34]. Other than metastasis in the lungs and bones, osteosarcoma could metastasize to other locations such as the lymph nodes and soft tissue. Because these cases are rare, only distant metastases as a whole were analyzed. The present analysis further demonstrated a diagnostic accuracy of ${ }^{18}$ F-FDG uptake in metastatic lesions with an AUC of 0.9639 and ${ }^{*} \mathrm{Q}$ of 0.9103 .

Misdiagnoses of ${ }^{18} \mathrm{~F}-\mathrm{FDG}$ PET and PET/CT are attributable to multiple reasons. Three included studies [34-36] showed higher FN and FP than the others because one study [35] detected local recurrence in patients with extremity osteosarcoma treated with surgical resection and endoprosthetic replacement and another two studies [34, 36] involved newly diagnosed with high grade osteosarcoma or initial staging osteosarcoma patients. Increased ${ }^{18} \mathrm{~F}$-FDG uptake is not pathognomonic for malignancy. Some benign lesions, such as giant cell tumors of the bones, inflammatory disease and fractures are presented with a high level of tracer accumulation [6]. Among these, inflammatory disease is the most 
commonly encountered causes of a false positive. Therefore, the findings of ${ }^{18} \mathrm{~F}$-FDG PET/CT for malignant lesions should be confirmed with a histopathology examination or follow-up. Meanwhile, some false negative cases are unavoidable. One cause is the nonspecific ${ }^{18} \mathrm{~F}$-FDG uptake in malignant diseases and asymmetric ${ }^{18}$ F-FDG distribution. Second, because of the limited spatial resolution of ${ }^{18} \mathrm{~F}$-FDG PET, some occult or sub-centimeter lesions could not be identified. Currently, the high cost of ${ }^{18} \mathrm{~F}-\mathrm{FDG}$ PET and PET/CT discourages their use in developing countries [52-54]. However, considering their satisfactory performance, as demonstrated by the present investigation, and the poor prognosis of osteosarcoma, especially for those with recurrence or distant metastases, patients may benefit from evaluation with ${ }^{18}$ F-FDG PET or PET/CT.

Some limitations of this meta-analysis merit considerations. First, the present analysis was a meta-analysis and systemic review; therefore, we were only able to analyze questions on the study level instead of on the patient level. Second, as a result of a lack of publications assessing the effectiveness of ${ }^{18} \mathrm{~F}$-FDG PET and PET/CT for detecting osteosarcoma, several sub-group analyses in our investigation were performed on a small number of studies. Third, there was methodological variability in the included studies, such as in the SUV, reference standards tests and duration of follow-up. Furthermore, some studies were assessed using ${ }^{18} \mathrm{~F}$-FDG PET, while others were assessed with PET/CT. Finally, some information was not available in the included studies.

\section{Conclusions}

In summary, our comprehensive meta-analysis of publications demonstrated that ${ }^{18} \mathrm{~F}$-FDG PET/CT have an excellent accuracy in the diagnosis, staging and recurrence monitoring of osteosarcoma. ${ }^{18} \mathrm{~F}$-FDG-avid lesions should be further examined in osteosarcoma, especially for suspicious lung lesions. To support the current conclusions, larger-scale trials should now be conducted.

\section{Abbreviations}

${ }^{18} \mathrm{~F}$-FDG: 18F-fluorodeoxyglucose; AUC: Area under the curve; Cl: Confidence interval; CT: Computed tomography; DOR: Diagnostic odd ratio; FN: Falsenegative; FP: False-positive; MRI: Magnetic resonance imaging; NLR: Negative likelihood ratio; PET: Positron emission tomography; PLR: Positive likelihood ratio; PRISMA: Preferred Reporting Items for Systematic Reviews and MetaAnalyses; SROC: The summary receiver operating characteristic curve; SUV: Standardized uptake value; TN: True negative; TP: True-positive
}

\section{Acknowledgements}

I would like to express my very great appreciation to Roland M. Klar for his valuable and constructive suggestions during the planning and development of this work.

\section{Funding}

This study was funded by the Key R \& D program in Shandong Province (Jinlei Dong, NO. 2016GSF201214) and the China Scholarship Council

(Fanxiao Liu, No. 201808080126). The funding agencies were not involved in the design of the study and collection, analysis, and interpretation of data and in writing the manuscript.

\section{Availability of data and materials}

All data analyzed during this study are included in this published article.

\section{Authors' contributions}

LFX contributed to the idea of this study. LFX, ZQY and DJ searched literatures and screened them independently. Any disagreement was solved by consulting the senior authors (DJL). LFX, ZQY and DJL screened data from the eleven final articles and make Tables. LFX and ZQY played an important role in analyzing the outcomes. LFX and ZQY conducted the data analyses and make graphs. LFX, ZQY, ZDS and DJL wrote the first draft. LFX, ZQY, ZDS and DJL revised the manuscript. LFX, ZQY, ZDS and DJL polished the draft. LFX, ZQY, ZDS and DJL approved the final version.

\section{Ethics approval and consent to participate}

This article does not contain any studies with human participants or animals performed by any of the authors.

\section{Consent for publication}

Not applicable.

\section{Competing interests}

The authors declare that they have no competing interests.

\section{Publisher's Note}

Springer Nature remains neutral with regard to jurisdictional claims in published maps and institutional affiliations.

\section{Author details}

'Department of Orthopaedics, Shandong Provincial Hospital affiliated to Shandong University, No.324, Road Jing Wu Wei Qi, Jinan 250021, Shandong, China. ${ }^{2}$ Department of Orthopaedic Surgery, Physical Medicine and Rehabilitation, University Hospital of Munich (LMU), Campus Grosshadern, Marchioninistrasse 23, 81377 Munich, Germany. ${ }^{3}$ Department of Orthopeadics, Qilu Hospital, Shandong University, Jinan, Shandong, China.

Received: 22 November 2018 Accepted: 19 March 2019

Published online: 05 April 2019

\section{References}

1. Biermann JS, Adkins DR, Agulnik M, Benjamin RS, Brigman B, Butrynski JE, Cheong D, Chow W, Curry WT, Frassica DA, et al. National comprehensive cancer network. J Natal Comp Can Newt. 2013;11(6):688-723.

2. Mirabella L, Trios RJ, Savage SA. Osteosarcoma incidence and survival rates from 1973 to 2004: data from the surveillance, epidemiology, and end results program. Cancer. 2009:115(7):1531-43.

3. Su W, Lai Z, Wu F, Lin Y, Mo Y, Yang Z, Wu J. Clinical efficacy of preoperative chemotherapy with or without ifosfamide in patients with osteosarcoma of the extremity: meta-analysis of randomized controlled trials. Med Oncol. 2015;32(2):481.

4. Yin K, Liao Q, Zhong D, Ding J, Niu B, Long Q, Ding D. Meta-analysis of limb salvage versus amputation for treating high-grade and localized osteosarcoma in patients with pathological fracture. Exp Ther Med. 2012; 4(5):889-94

5. Takeuchi A, Lewis VO, Satcher RL, Moon BS, Lin PP. What are the factors that affect survival and relapse after local recurrence of osteosarcoma? Clin Orthop Relat Res. 2014:472(10):3188-95.

6. Peller PJ. Role of positron emission tomography/computed tomography in bone malignancies. Radiol Clin N Am. 2013;51(5):845-64.

7. Palmerini $E$, Colangeli M, Nanni C, Fanti S, Marchesi E, Paioli A, Picci P, Cambioli $S$, et al. The role of FDG PET/CT in patients treated with neoadjuvant chemotherapy for localized bone sarcomas. Eur J Nucl Med Mol Imaging. 2017:44(2):215-23.

8. Quartuccio N, Treglia G, Salsano M, Mattoli MV, Muoio B, Piccardo A, Lopc E, Cistaro A. The role of Fluorine-18-Fluorodeoxyglucose positron emission tomography in staging and restaging of patients with osteosarcoma. Radiol Oncol. 2013;47(2):97-102.

9. Liu F, Zhang Q, Zhu D, Li Z, Li J, Wang B, Zhou D, Dong J. Performance of positron emission tomography and positron emission tomography/ 
computed tomography using Fluorine-18-Fluorodeoxyglucose for the diagnosis, staging, and recurrence assessment of bone sarcoma: a systematic review and meta-analysis. Medicine (Baltimore). 2015;94(36):e1462.

10. Huang T, Li F, Yan Z, Ma Y, Xiong F, Cai X, Zhang Q, Liu F, et al. Effectiveness of 18F-FDG PET/CT in the diagnosis, staging and recurrence monitoring of Ewing sarcoma family of tumors: a meta-analysis of 23 studies. Medicine (Baltimore). 2018;97(48):e13457.

11. Whiting P, Rutjes AW, Reitsma JB, Bossuyt PM, Kleijnen J. The development of QUADAS: a tool for the quality assessment of studies of diagnostic accuracy included in systematic reviews. BMC Med Res Methodol. 2003;3:25.

12. Liberati A, Altman DG, Tetzlaff J, Mulrow C, Gøtzsche PC, loannidis JP, Clarke $M$, Devereaux PJ, et al. Preferred reporting items for systematic reviews and meta-analyses: the PRISMA statement. PLoS Med. 2009;6(7):e1000097.

13. Kole AC, Nieweg OE, Hoekstra HJ, van Horn JR, Koops HS, Vaalburg W. Fluorine-18-fluorodeoxyglucose assessment of glucose metabolism in bone tumors. J Nucl Med. 1998;39(5):810-5.

14. Schulte M, Brecht-Krauss D, Werner M, Hartwig E, Sarkar MR, Keppler P, Kotzerke J, Guhlmann A, et al. Evaluation of neoadjuvant therapy response of osteogenic sarcoma using FDG PET. J Nucl Med. 1999;40(10):1637-43.

15. Schulte M, Brecht-Krauss D, Heymer B, Guhlmann A, Hartwig E, Sarkar MR, Diederichs CG, Von Baer A, et al. Grading of tumors and tumorlike lesions of bone: evaluation by FDG PET. J Nucl Med. 2000;41(10):1695-701.

16. Franzius C, Sciuk J, Daldrup-Link HE, Jürgens H, Schober O. FDG-PET for detection of osseous metastases from malignant primary bone tumours: comparison with bone scintigraphy. Eur J Nucl Med. 2000;27(9):1305-11.

17. Franzius C, Daldrup-Link HE, Sciuk J, Rummeny E, Bielack S, Jürgens H, Schober O. FDG-PET for detection of pulmonary metastases from malignant primary bone tumors: comparison with spiral $\subset$. Ann Oncol. 2001;12(4):479-86.

18. Franzius C, Daldrup-Link HE, Wagner-Bohn A, Sciuk J, Heindel WL, Jürgens H, Schober O. FDG-PET for detection of recurrences from malignant primary bone tumors: comparison with conventional imaging. Ann Oncol. 2002; 13(1):157-60.

19. Yanagawa T, Watanabe H, Inoue T, Ahmed AR, Tomiyoshi K, Shinozaki T, Oriuchi N, Endo K, et al. Carbon-11 choline positron emission tomography in musculoskeletal tumors: comparison with fluorine-18 fluorodeoxyglucose positron emission tomography. J Comput Assist Tomogr. 2003;27(2):175-82.

20. Kneisl JS, Patt JC, Johnson JC, Zuger JH. Is PET useful in detecting occult nonpulmonary metastases in pediatric bone sarcomas? Clin Orthop Relat Res. 2006;450:101-4.

21. lagaru A, Quon A, MCDougall IR, Gambhir SS. F-18 FDG PET/CT evaluation of osseous and soft tissue sarcomas. Clin Nucl Med. 2006;31(12):754-60.

22. Völker T, Denecke T, Steffen I, Misch D, Schönberger S, Plotkin M, Ruf J, Furth $C$, et al. Positron emission tomography for staging of pediatric sarcoma patients: results of a prospective multicenter trial. J Clin Oncol. 2007;25(34):5435-41.

23. Shin DS, Shon OJ, Han DS, Choi JH, Chun KA, Cho IH. The clinical efficacy of 18F-FDG-PET/CT in benign and malignant musculoskeletal tumors. Ann Nucl Med. 2008;22(7):603-9.

24. Charest M, Hickeson M, Lisbona R, Novales-Diaz JA, Derbekyan V, Turcotte RE. FDG PET/CT imaging in primary osseous and soft tissue sarcomas: a retrospective review of 212 cases. Eur J Nucl Med Mol Imaging. 2009;36(12):1944-51.

25. Hawkins DS, Conrad EU 3rd, Butrynski JE, Schuetze SM, Eary JF. [F-18] -fluorodeoxy-D-glucose-positron emission tomography response is associated with outcome for extremity osteosarcoma in children and young adults. Cancer. 2009;115(15):3519-25.

26. Benz MR, Czernin J, Tap WD, Eckardt JJ, Seeger LL, Allen-Auerbach MS, Dry SM, Phelps ME, Weber WA, Eilber FC. FDG-PET/CT imaging predicts histopathologic treatment responses after neoadjuvant therapy in adult primary bone sarcomas. Sarcoma. 2010;2010:143540.

27. Lindholm P, Sutinen E, Oikonen V, Mattila K, Tarkkanen M, Kallajoki M, Aro H, Böhling T, et al. PET imaging of blood flow and glucose metabolism in localized musculoskeletal tumors of the extremities. Nucl Med Biol. 2011 38(2):295-300

28. Cistaro A, Lopci E, Gastaldo L, Fania P, Brach Del Prever A, Fagioli F. The role of $18 \mathrm{~F}-\mathrm{FDG}$ PET/CT in the metabolic characterization of lung nodules in pediatric patients with bone sarcoma. Pediatr Blood Cancer. 2012;59(7):1206-10.

29. lagaru A, Quon A, McDougall IR, Gambhir SS. Clinical experience of 18F-FDG PET/CT in soft tissue and osseous sarcomas. UHOD-Uluslararasi HematolojiOnkoloji Dergisi. 2012;22(3):163-9.
30. Bandopadhyaya GP, Gupta P, Singh A, Shukla J, Rastogi S, Kumar R, Malhotra A. (99m) Tc-DMSA (V) in evaluation of osteosarcoma: comparative studies with (18) F-FDG PET/CT in detection of primary and malignant lesions. ISRN Oncol. 2012;2012:371830.

31. Byun BH, Kong CB, Lim I, Kim Bl, Choi CW, Song WS, Cho WH, Jeon DG, et al. Comparison of (18) F-FDG PET/CT and (99 m) Tc-MDP bone scintigraphy for detection of bone metastasis in osteosarcoma. Skelet Radiol. 2013;42(12):1673-81.

32. Kong CB, Byun BH, Lim I, Choi CW, Lim SM, Song WS, Cho WH, Jeon DG, et al. 18F-FDG PET SUVmax as an indicator of histopathologic response after neoadjuvant chemotherapy in extremity osteosarcoma. Eur J Nucl Med Mol Imaging. 2013;40(5):728-36.

33. Bai CJ, Zhu R, Fang ZW. A comparison between preoperative PET/CT and $\mathrm{CT}$ images of long bone osteosarcoma of the lower extremity. Acad J Second Mil. 2013;34(1):100-3.

34. Quartuccio N, Fox J, Kuk D, Wexler LH, Baldari S, Cistaro A, Schöder H. Pediatric bone sarcoma: diagnostic performance of 18F-FDG PET/CT versus conventional imaging for initial staging and follow-up. Am J Roentgenol. 2015;204(1):153-60.

35. Chang K, Kong CB, Cho WH, Jeon DG, Lee SY, Lim I, Lim SM. Usefulness of increased 18F-FDG uptake for detecting local recurrence in patients with extremity osteosarcoma treated with surgical resection and endoprosthetic replacement. Skelet Radiol. 2015;44(4):529-37.

36. Hurley C, McCarville MB, Shulkin BL, Mao S, Wu J, Navid F, Daw NC, Pappo AS, et al. Comparison of 18F-FDG-PET-CT and bone scintigraphy for evaluation of osseous metastases in newly diagnosed and recurrent osteosarcoma. Pediatr Blood Cancer. 2016;63(8):1381-6.

37. Sharp SE, Shulkin BL, Gelfand MJ, McCarville MB. FDG PET/CT appearance of local osteosarcoma recurrences in pediatric patients. Pediatr Radiol. 2017; 47(13):1800-8.

38. Angelini A, Ceci F, Castellucci P, Graziani T, Polverari G, Trovarelli G, Palmerini E, Ferrari S, et al. The role of 18F-FDG PET/CT in the detection of osteosarcoma recurrence. Eur J Nucl Med Mol Imaging. 2017;44(10):1712-20.

39. Choi YY, Kim JY, Yang SO. PET/CT in benign and malignant musculoskeletal tumors and tumor-like conditions. Semin Musculoskelet Radiol. 2014;18(2):133-48.

40. Hongtao L, Hui Z, Bingshun W, Xiaojin W, Zhiyu W, Shuier Z, Aina H, Yuanjue S, et al. 18F-FDG positron emission tomography for the assessment of histological responseto neoadjuvant chemotherapy in osteosarcomas: a meta-analysis. Surg Oncol. 2012;21(4):e165-70.

41. Bastiaannet E, Groen H, Jager PL, Cobben DC, van der Graaf WT, Vaalburg W, Hoekstra HJ. The value of FDG-PET in the detection, grading and response to therapy of soft tissue and bone sarcomas: a systematic review and meta-analysis. Cancer Treat Rev. 2004;30(1):83-101.

42. Costelloe CM, Chuang HH, Daw NC. PET/CT of osteosarcoma and Ewing sarcoma. Semin Roentgenol. 2017;52(4):255-68.

43. Boas FE, Fleischmann D. Evaluation of two iterative techniques for reducing metal artifacts in computed tomography. Radiology. 2011;259(3):894-902.

44. Garcia R, Kim EE, Wong FC, Korkmaz M, Wong WH, Yang DJ, Podoloff DA. Comparison of fluorine-18-FDG PET and technetium-99m-MIBI SPECT in evaluation ofmusculoskeletal sarcomas. J Nucl Med. 1996;37(9):1476-9.

45. Zhuang H, Chacko TK, Hickeson M, Stevenson K, Feng Q, Ponzo F, Garino JP, Alavi A. Persistent non-specific FDG uptake on PET imaging following hip arthroplasty. Eur J Nucl Med Mol Imaging. 2002;29(10): 1328-33.

46. Heiba SI, Luo J, Sadek S, Macalental E, Cacavio A, Rosen G, Abdel-Dayem HA. Attenuation-correction induced artifact in F-18 FDG PET imaging following Total knee replacement. Clin Positron Imaging. 2000;3(6):237-9.

47. Zou H, Zhao Y. ${ }^{18}$ F-FDG PET-CT for detecting gastric cancer recurrence after surgical resection: ameta-analysis. Surg Oncol. 2013;22(3):162-6.

48. Poulou LS, Ziakas PD, Ziogas DC, Doxani C, Xyla V, Vakrinos G, Voulgarelis M, Thanos L. FDG-PET for detecting local tumor recurrence of ablated liver metastases: a diagnostic meta-analysis. Biomarkers. 2012;17(6):532-8.

49. Zhao H, Yao Y, Wang Z, Lin F, Sun Y, Chen P. Therapeutic effect of pirarubicin-based chemotherapy for osteosarcoma patients with lung metastasis. J Chemother. 2010;22(2):119-24.

50. Bacci G, Longhi A, Bertoni F, Briccoli A, Versari M, Pignotti E, Picci P. Bone metastases in osteosarcoma patients treated with neoadjuvant or adjuvant chemotherapy: the Rizzoli experience in 52 patients. Acta Orthop. 2006; 77(6):938-43.

51. San-Julian M, Diaz-de-Rada P, Noain E, Sierrasesumaga L. Bone metastases from osteosarcoma. Int Orthop. 2003;27(2):117-20. 
52. Wang YT, Huang G. Is FDG PET/CT cost-effective for pre-operation staging of potentially operative non-small cell lung cancer? - from Chinese healthcare system perspective. Eur J Radiol. 2012;81(8):e903-9.

53. Keith CJ, Miles KA, Griffiths MR, Wong D, Pitman AG, Hicks RJ. Solitary pulmonary nodules: accuracy and cost-effectiveness of sodium iodide FDGPET using Australian data. Eur J Nucl Med Mol Imaging. 2002;29(8):1016-23.

54. Cafarella TA. How to make PET cost effective. J Nucl Med. 1995;36(5):42N.

Ready to submit your research? Choose BMC and benefit from:

- fast, convenient online submission

- thorough peer review by experienced researchers in your field

- rapid publication on acceptance

- support for research data, including large and complex data types

- gold Open Access which fosters wider collaboration and increased citations

- maximum visibility for your research: over $100 \mathrm{M}$ website views per year

At $\mathrm{BMC}$, research is always in progress.

Learn more biomedcentral.com/submissions 